\title{
Are Browse-wrap Agreements Legally Binding: As Analysed Across Multiple Jurisdictions
}

\author{
Aashana Chandak \\ Final year student pursuing B.B.A. L.L.B. (Hons.) at Jindal Global Law School \\ O.P. Jindal Global University. Paper was first written in October, 2019.
}

\begin{abstract}
Browse-wrap agreements are e-contracts that lack the element of express consent which creates ambiguity in their enforcement across countries like India and Canada. The United States of America has through a plethora of case laws attempted to follow a framework with a adequate communication of notice system which is subjected to consumer protection concerns. With the recent enforcement of the General Data Protection Regulations(GDPR)in the European Union it has led to the complete abandonment of the browse-wrap agreements due to the lack of the consentbeing explicitly provided. Leading to the rise in the recognition of theclick-wrap agreements being adopted as a standardized form of e-commerce contracts across jurisdictions.
\end{abstract}

\section{INTRODUCTION}

Innovation and technological companies areracing to adopt a strongeronline business model through applications, websites and online portals. An electronic contract is drafted, executed and finally enacted in electronic form such as click-wrap agreements or browsewrap agreements that bind the consumer under specific terms and conditions as per the set out contractual obligations.

The e-commerce industry is thriving due to online agreements between the user and website holder which makes it easier for companies to sell or license products and services.Making electronic agreementsomnipresent in the digital commercial marketplace. ${ }^{1}$

\section{BROWSE-WRAP AGREEMENTS}

Browsewrapagreements can be read or accessed simply by clicking on a hyperlink from the website. ${ }^{2}$ Such hyperlink is usually indicated as, 'Terms of Service', 'Conditions of Use' or 'Legal Terms'. ${ }^{3}$ Under browse-wrap agreements the consumer may not need to provide explicit consent by specifically clicking on any tab. These agreements are enforceable depending on the manner in which the website chooses to communicate the terms and

\footnotetext{
${ }^{1}$ ProCD, Inc. v. Zeidenberg (1996) 86 E3d 1447 (7th Cir.)

${ }^{2}$ Sutatip Yuthayotin, Access to Justice in Transnational B2C E-Commerce: A Multidimensional Analysis of Consumer Protection Mechanisms (1st edn, Springer 2014) 113

${ }^{3}$ Nancy S. Kim, Wrap Contracts: Foundations and Ramifications (1st edn, Oxford University Press, 2013) 10
}

conditions to the user.Making the consumer bound by the relevant terms once the website isused by him or in some cases, immediately when the user moves beyond the homepage thebrowse wrap agreement becomes binding upon such user. Therefore, this evidences the lack of clear link of consent being communicated by the user. Which makes the regulation of a browse wrap agreement extremely difficult to enforce in courts due to the lack of clarity of the chain of events that lead to the eventual acceptance of such an online agreement.

\section{CLICK WRAP AGREEMENTS V. BROWSER WRAP AGREEMENTS}

Whereas clickwrap agreements have the necessary requirement of undertaking explicit consent before forming an online agreement. As the name suggests a 'click' on the 'I agree' boxwhich once selected removes all scope of ambiguity in the enforcement of such contractual relations that may arise on a online consumer. However it is pertinent to note, the threshold forconsentof a browse-wrap agreement is inherently different from that of a click-wrap agreement. Where under a browse wrap agreement the user's consent can be inferred from the mere usage of the website.Prima facie making clickwrap agreements the safer, more reliable and legally better alternative as using the browser-wrap agreementprovidesexcessive wiggle room for the website holders. ${ }^{4}$ Over the years the clickwrap agreement model has been revised and adopted worldwide with increasing acceptance due to the integral element of explicit consent ensuring clarity of contractual relations between theconcerned parties. The browse wrap agreement model still requires immense refining and wider acceptance throughout jurisdictions to establish a strengthened degree of enforceability in the e-commerce sector.

\section{ESSENTIALITY OF COMMUNICATION}

Under browser-wrap agreements there is no explicit communication regarding the terms of service to a user. This is because consumer can browse throughout the entire website without being directed to the terms of serviceunlike in the clickwrap agreement model. The e-commerce industryruns on ideas such as smoother functioning with

${ }^{4}$ Pillsbury Winthrop Shaw Pittman LLP 'How Binding is your Browse-wrap Agreement'(Lexology, 2016) <https://www.lexology.com/library/detail.aspx?g=4b4b93d a-c40a-4724-916c-3bdd9011698d accessed October 25, 2019> 
easier accessso that consumerscan order products from the comfort of their homes. Using a recurring terms and conditions notification box or adopting a clickwrap agreement system at each stageas one browses through a website may deter the consumer from making future visits to the website. However, despite the consequence of thistedious scenario, itdoes not exonerate the website holdersfrom their liability to seek clear consent. As the service providers have a responsibility to ensure the minimum initial communication threshold of terms of use is met with in order to promote awareness on the consumers end. ${ }^{5}$ Adequate communication of terms leads to a transparent manner in which browse-wrap agreements can be recognized. The notice of a browse-wrap agreement is provided through the conspicuous display of the relevant terms under the contract making them effectively incorporated through reference in the form of a hyperlink. ${ }^{6}$ Therefore it is essential for website holders to communicate the relevant terms and conditions in a standard and acceptable manner. ${ }^{7}$ In the absence of acceptance of adequately communicated of notice the enforceability of the browser-wrap agreement will be challenging.

\section{CANADA}

The Canadian Supreme Court case Century 21 Canada Ltd. Partnership v. Rogers Communications Inc ${ }^{8}$ ruled on the degree of enforceability of browse-wrap agreement when used to communicate the relevant terms deciding that there was sufficient notice and the defendant was undisputedly aware of the relevant terms. However in this case there was the elements of a physical delivery of letter to the user making it an ironclad case. Therefore, theCanadian Courts have held that browse-wrap agreements are enforceable when the consumer has notice of the websites relevant terms. ${ }^{9}$ The Canadian laws make adistinction between click-wrap and browse-wrap agreements based on consumer protection considerations as under a click-wrap agreement the opportunity to identify and give clear consent exists with the user ensuring certainty. ${ }^{10}$ Whereas, the element of certainty may not exist under a browse-wrap agreement leaving the consumers vulnerable to exploitation as the terms and conditions may be inconsistent with the legal policies when hyperlinked as

\footnotetext{
5 Indranath Gupta, 'Are websites adequately communicating terms \& conditions link in a browse-wrap agreement?' (2012) $\quad 3 \quad$ (2) EJLT <http://ejlt.org/article/view/47> accessed 26 October, 2019 ${ }^{6}$ Pollstar v. Gigmania Ltd., (E.D. Cal. 2000), 170 F Supp. 2d 974, 981

${ }^{7}$ Melissa Robertson, 'Is Assent still a pre-requisite for contract formation in today's E-conomy' (2003) 78 WLR 265

8 Century 21 Canada Ltd. Partnership v. Rogers Communications Inc., (2011) BCSC 1196 BA 6

${ }^{9}$ Ibid.

${ }^{10}$ Deborah Louise Douez v. Facebook Inc. 2017 SCC 33
}

they will not be directly viewed by the user, hindering business structures on the internet. ${ }^{11}$

\section{UNITED STATES OF AMERICA}

Unlike the click-through agreements, browse-wrap agreements do not follow the samemethodologyas their terms of service are not similarly structured, whereby the users tend to be unaware of the terms they are consenting to. Website design elements are key to browse-wrap agreements as observedthroughout existing American jurisprudence. Their courts have been critical of elements such as the proximity and recurrence of the terms of hyperlink $^{12}$, the size, colour and background of the font ${ }^{13}$, placement of the hyperlink on the webpage at a suitable position not being at the bottom or in the midst of other links. ${ }^{14}$ The hyperlink being placed at the bottom of the webpage and how it works against the requirement of adequate communication for the consumers has remained one of the most commonly recurring issues. ${ }^{15}$ In the recent case of Long v. Provide Commerce Inc. ${ }^{16}$ thecourt considered various website design elements such as the placement of the hyperlinks on the webpages, their size, proximity to other hyperlinks, and font colors in relation to the webpage background colors, among other things. Concluding that hyperlinks and design had failed to provide the user with constructive notice of the terms of use ${ }^{17}$ as the placing a hyperlink to the terms of service, even if the hyperlink is conspicuous was insufficient to place constructive notice on the consumer. Naming a conspicuous hyperlink as the "Terms of Service or Use" may not be sufficient, to put a user on constructive notice of the terms.In the Hubbert v. Dell Corpcase ${ }^{18}$ consumers were repeatedly shown the terms of service, along with a conspicuous hyperlink, over a series of pages. The court finally observed that repeated exposure and visual effects are needed to put a reasonable person on notice of the relevant terms. ${ }^{19}$ The concept of constructive notice is similar to that the concept of explicit consent requirement under EU laws.

Lastly, the case of Rushing v. Viacom ${ }^{20}$ where it was alleged that Viacom violated privacy laws by tracking and selling information on children as they played a mobile game. Viacom requested a stay pending arbitration as per Viacom's user agreement. The court found that there was no obvious evidence of actual or constructive notice to the

\footnotetext{
${ }^{11}$ Deborah Louise Douez v. Facebook Inc. 2016 SCC (Motion for Intervention) (18)

${ }^{12}$ Nguyen v. Barnes \& Noble Inc. (2014) 763 F.3d 1171

${ }^{13}$ Pollstar v. Gigmania (2000) 170 F.Supp. 2d 974

${ }^{14}$ Specht v. Netscape Communication Corp (2002) 306 F.3d 17

${ }^{15}$ Ibid. n.13

${ }^{16}$ Long v. Provide Commerce Inc (2016)245 Cal. App. 4th 855

${ }^{17}$ Ibid

${ }^{18}$ Hubbert v. Dell Corp., (2005) WL 1968774

${ }^{19}$ Ibid.

${ }^{20}$ Rushing v. Viacom (2018) N.D. Cal 04492
} 
user, as they had to further click on the option 'more' to review arbitration terms. Automatically making the contentious arbitration provisions in their browse wrap agreement unenforceable as an arbitration is a contractual matter and silence or inaction cannot amount to legal acceptance. ${ }^{21}$

These case laws discussed show how the courts have followed a few steps to better understand the laws that regulates browse-wrap agreements. The first requirement of notice isfollowed by whether the conditions were fair when consent was received. These two steps form the information of the concerned contract. Lastly the third step concerns the protection of consumers. Consumer protection terms under the browse wrap agreement arise from the need to maintain fairness and equity to ensure personal information and privacy breaches do not occur, ensuring the browse wrap agreement model is not exploited. ${ }^{22}$. Laws such as in the American state of California has made a privacy statements to be made an essential part of the homepage or the immediate significant page on the websites. Additionally almost all 100 of the top commercial webpages have posted delineatedprivacy policies ${ }^{23}$.

A user who completes a click-wrap has both actual notice of the terms and has assented to those conditions, terms presented in a clickwrap agreement are generally enforceable contracts. Whereas under browse-wrap as no affirmative action is required by the website user to agree to the terms of a contract other than his or her use of the website for browse-wrap agreements and can only be enforced when the user has actual knowledge of the agreement or when the website makes the terms and conditions so conspicuous that the website is deemed to put a reasonably prudent person on inquiry notice. The validity of the browse-wrap agreement turns on the assessment of the design and content of the website. It is explained that a browse-wrap agreement can be enforceable when a user admits that he knew perfectly well what terms were imposed. Therefore the browse wrap agreement must be sufficiently conspicuous, accessible and must notify the consumer that continued use of the webpage will be equated to manifestation of the users intention to consent to the relevant terms of service.

\section{INDIA}

With the expanse of the e-commerce industry the revenue coming in through these portals is constantly rising.No specific legislation exists within the domestic laws of India that governs e-contracts. It would be difficult for the companies involved in these businesses to carve out separate agreements for each user, pre-determined standardized forms such as browse-wrap agreements solve

\footnotetext{
${ }^{21}$ Ibid.

${ }^{22}$ Ian Rambarran and Robert Hunt, 'Are Browse-Wrap Agreements All They Are Wrapped up to Be' (2007) 9 Tul J Tech \& Intell Prop 173

${ }^{23}$ Ibid.
}

this problem if they can meet the essentials of a traditional contract such as freedom to contract and free consent arise. Indian laws such as the Indian contract law holds a wide interpretation such as S.16 which deals with inequality amongst the parties involved causing unfair advantage of one party over another, as per undue influence as it accounts for absence of meaningful choice which is a problem regarding appropriate assent in relation to browse wrap agreements. ${ }^{24}$ In online contracts, chances of misrepresentation are high.As the Indian Contract Act, 1872 does not provide for any express provision that can regulate such type of browse wrap agreement. However, in the 103rd Law Commission Report, a recommendation was made suggesting creating a separate chapter-IVA and introducing section 67A, where the judiciary should have the power to refuse enforcement of a contract or any part that it holds as unconscionable. ${ }^{25}$ These agreements are forms of electronic contracts making them enforceable under S.65B of the Evidence Act. Lastly the existing consumer protection laws and Information Technology Act, 2002 have not completely evolved to the extent to safely govern these e-contracts.

India needs to create regulations for browse wrap agreements as the portals that are used in the United States, EU are a part of the Indian markets as well. For the smoother functioning of the this sector the Govt. has issued the Draft National E-commerce Policy, $2019^{26}$ which strategies a framework for consumer protection with an online portal for redressal of grievances making available compensation to the aggrieved electronically along with the imminent need to develop a legal framework as suggested. Other suggestions under the draft policy are the restrictions on cross- border flow of data generated through ecommerce, search engine and such platforms ensuring a stricter regulation for data privacy protection. ${ }^{27}$

Conclusively, aside from the need for consumer protection requirements clickwrap agreements are recognized in India due to their explicit consent requirement where unlike browse wrap agreement there exists no element of ambiguity making it a better solution for most e-commerce platforms to adopt and enforce. The binding nature of browse-wrap agreements is yet to be tested before the Indian courts.

\section{EUROPEAN UNION AND THE GDPR}

Unlike the United States of America theEuropean Union has controlled and regulated electronic communications and internet based services to primarily protect consumer privacy and this has been carried out without creating economic constraints on the collective

\footnotetext{
${ }^{24}$ Sanskriti Rastogi, Consumer Interest and Electronic Contracts: An urgent need for International Protocol (2014) SCCOnline 4,5

25 Sagnik Sarkar, Understanding and Analysing the Legality of E-Contracts (2018) WJJP 1

${ }^{26}$ Draft National E-Commerce Policy, 2019

${ }^{27}$ Ibid.
} 
economy. ${ }^{28}$ Despite attempts to extend the rigid consumer privacy regime through international agreements the EU's progress has remained slow with big American firms contesting their intrusion into the American cyberspace. ${ }^{29}$ Transparency is at the heart of the General Data Protection Regulationinforming consumers how and who is processing their data, whether the information given is being altered or erased formulate the key tenets of the regulation. Complex policies can no more provide an advantage to the website holder as the GDPR increases the scrutiny, requiring it to be written in clear language keeping an ordinary individual in mind. The consent threshold under GDPR has nearly wiped out the use of browse wrap agreements as legal under European Union and entities carrying on business with the countries of the EU. ${ }^{30}$ Clickwrap agreement is the best option to gain clear affirmative consent as the user has to actively select through physical action that they consent. Ensuring there is zero ambiguity, notice and adequate communication problems. Lastly the litigation involving browse wrap agreements can be simply ignored by the use of a click wrap agreement as the user and the website holder sufficiently comply with the meeting of the minds and clear terms of contract. Without consent information cannot be collected under the regulation of the GDPR.

\section{CONCLUSION}

The cases in the United States and Canada indicate the fact that the responsibility of adequate communication and notice to the user rests wholly on the website holders. However, the regulation of browse-wrap agreements through an advanced framework is the need of the hour. With the onset of rapid technological advancements consumer protection from the enforcement of such econtracts in the form of browse-wrap agreements is essential to protect the privacy concerns of the consumers data. Despite, certain jurisdictions having fairly advanced court findings which loosely formulate a framework for browse wrap agreements the judgements are varying as per the facts of each of the cases. The understanding and laws concerning a click-wrap agreement are at a much more developed stage and the model used provides clarity on consent of the user ensuring that the parties in the econtract sufficiently satisfy the meeting of minds component under contractual laws. With the advent of the General Data Protection Regulation a standardized format for e-commerce contractual agreements is required to be

${ }^{28}$ Charles E. MacLean, It Depends: Recasting Internet Clickwrap, Browsewrap, "I Agree," and Click- rough Privacy Clauses as Waivers of Adhesion, 65 Clev. St. L. Rev. $43 \quad$ (2017) accessed on <ps://engagedscholarship.csuohio.edu/clevstlrev/vol65/iss1 /7>

${ }^{29}$ Eugene Volokh, Freedom of Speech and Information Privacy: The Troubling Implications of A Right to Stop People from Speaking About You, 52 STAN. L. REV. 1049, 1053-54 (2000).

${ }^{30}$ General Data Protection Regulation 2016/679 created as big companies are servicing consumers across borders.

After considering multiple jurisdictional positions, existing laws and frameworks it is observed that the browse-wrap agreement does not hold a strong enough legally binding position as compared to the existing comprehensive framework of click-wrap agreements making them more preferable due to their ease in enforcement. 